\title{
The immunology of neurodegeneration
}

\author{
Eva Czirr and Tony Wyss-Coray
}

\author{
Department of Neurology and Neurological Sciences, Stanford University School of Medicine, Stanford, California, USA. \\ Center for Tissue Regeneration, Repair and Restoration, VA Palo Alto Health Care System, Palo Alto, California, USA.
}

\begin{abstract}
While immune responses in neurodegeneration were regarded as little more than a curiosity a decade ago, they are now increasingly moving toward center stage. Factors driving this movement include the recognition that most of the relevant immune molecules are produced within the brain, that microglia are proficient immune cells shaping neuronal circuitry and fate, and that systemic immune responses affect brain function. We will review this complex field from the perspective of neurons, extra-neuronal brain cells, and the systemic environment and highlight the possibility that cell intrinsic innate immune molecules in neurons may function in neurodegenerative processes.
\end{abstract}

\section{Introduction}

The immune system serves to protect the organism from external and internal danger by using an elaborate network of immune sensors. In the past, immunologists believed that most of these sensors served to detect pathogens, but there is a growing recognition, elegantly formulated by P. Matzinger (1), that the ability of immune sensors to recognize pathogens may have an evolutionary origin in the detection of molecules on distressed cells from within the organism itself. This point of view is of particular interest for our understanding of immune responses in neurodegeneration in the absence of pathogenic triggers. Importantly, immune sensors are not restricted to dedicated immune cells but specialized sensors are expressed by most cell types including neurons; what's more, immune sensors are also present inside cells, allowing them to detect internal dangers. Once triggered, the immune system can employ cellular or soluble arbiters, which attempt to remove the cause of injury and initiate repair processes, thereby employing all or part of what is called an inflammatory response. However, in the event that the injurious trigger cannot be removed, the immune response may turn into chronic inflammation or cell death.

It is now clear that the immune response forms an integral part of neurodegeneration, and we are gaining a better understanding of how this system may promote or inhibit neurodegenerative processes. The complement system and microglial cells, for example, are invariably activated in brain regions with neurodegeneration, and genetic studies in animal models demonstrate that these immune effectors can be either protective or harmful (Table 1). A growing number of studies also show associations between neurodegeneration in the brain or spinal cord and immune changes in the periphery. These findings have been discussed extensively (2-4) and will not be reiterated here. Instead, we explore immune responses in neurodegeneration at three levels: (a) cell-autonomous immune mechanisms in neurons, (b) immune responses in the extra-neuronal brain tissue, and (c) immune responses associated with neurodegeneration at a systemic level (Figure 1). Theoretically, neurodegeneration may start at any of these levels, and a failure of the immune responses at each of them may thus contribute to or result in neurodegeneration. While the basic understanding of immune responses in neurodegeneration is growing, the clinical implications for humans are still largely unclear.

Conflict of interest: The authors have declared that no conflict of interest exists. Citation for this article: JClin Invest. 2012;122(4):1156-1163. doi:10.1172/JCI58656.

\section{Immune responses by neurons}

Neurodegeneration ultimately targets neurons and can range from damage to synapses or neurites to cell death. It seems therefore obvious to ask whether cell autonomous immune responses in neurons may have a role in neurodegeneration. However, only in the past few years have scientists started to explore how neurons sense danger using intracellular or surface immune sensors (Figure 2). Once a danger signal is detected, neurons can activate intracellular defense mechanisms and can alert neighboring cells via cell-cell interactions or the release of signaling proteins, neurotransmitters, and other messengers.

Innate immune sensors of cell-autonomous distress. The best studied innate immune sensors are TLRs, which signal through various adaptor molecules to activate NF- $\mathrm{KB}$ and/or Stat signaling pathways to induce the production of mostly pro-inflammatory cytokines and chemokines (reviewed in ref. 5). Mammalian TLRs not only recognize pathogen-derived molecules such as lipoproteins, peptidoglycans, single-stranded RNA (ssRNA), double-stranded RNA (dsRNA), and unmethylated CPG motifs, but also endogenous molecules produced by stressed and injured cells, including hsp, mRNA, and fibrinogen. Neurons and neural progenitor cells express several TLRs, including TLR2, $-3,-4,-7 / 8$, and -9 , and their functions range from regulating neurogenesis to triggering neurite retraction or cell death (reviewed in ref. 6). Because TLRs can be functionally expressed in the ER and in endolysosomes $(7,8)$, molecules associated with injury or aging could in principle trigger a pathogenic cascade from within neurons. In support of this idea, mitochondrial DNA ( $m t D N A)$, which is released from damaged mitochondria, is recognized by TLR9 in the endosome and can lead to an inflammatory and injurious response (9). While very little is known at this point about the role of innate immune sensors in neurons, studies in macrophages show that stimulation of TLR $3,-4$, and -7 can be beneficial by inducing autophagy $(10,11)$. Autophagy, which is a degradation pathway for long-lived proteins and organelles (12), has largely beneficial functions in postmitotic neurons, and it is possible that damaged mitochondria or intracellular protein aggregates in aged neurons may trigger TLR-dependent autophagy for clean up. Defects in autophagy, as they occur in neurodegenerative diseases (13-16), might thus interfere with such an innate immune process.

Another group of innate immune sensors, nucleotide binding oligomerization domain-like (NOD-like) receptors, form cytosolic protein complexes called inflammasomes, which can activate caspase-1, IL-1, and NF-кB-dependent inflammatory responses $(17,18)$. Recent studies show that NOD-like receptors (NLR) can also trigger autophagy (19-21), which supports an intriguing link among 


\section{Table 1}

Genetic modifications in mouse models of neurodegenerative diseases: molecules with detrimental effects

\begin{tabular}{|c|c|c|c|c|}
\hline Molecule & Disease model for: & Genetic manipulation ${ }^{A}$ & Outcome & Reference \\
\hline $\mathrm{C} 1 \mathrm{q}$ & $A D$ & Deletion & Decreased neurodegeneration & 98 \\
\hline $\mathrm{C} 1 \mathrm{q}$ & Prion disease & Deletion & Prevention of prion disease & 99 \\
\hline C3 & Prion disease & Deletion & Delayed neuroinvasion & 99 \\
\hline Caspase-1 & ALS & Deletion & Extension of life span, decreased gliosis and neurodegeneration & 50 \\
\hline CCL2 & $A D$ & Overexpression in astrocytes & Increased plaque load & 100 \\
\hline CD14 & $A D$ & Deletion & Decreased plaque load & 101 \\
\hline CD21/CD35 & Prion disease & Deletion & Delayed neuroinvasion & 99 \\
\hline CD36 & $\mathrm{AD}$ & Deletion & $\begin{array}{l}\text { Decreased neurovascular dysfunction, reduced vascular } \\
\text { oxidative stress; no changes in plaque pathology }\end{array}$ & 102 \\
\hline CD40L & $A D$ & Deletion & Decreased plaque load and gliosis & 103 \\
\hline Crry & $A D$ & $\begin{array}{l}\text { Overexpression under } \\
\text { metallothionein promotor }\end{array}$ & Increased plaque load and neurodegeneration & 104 \\
\hline CX3CR1 & $A D$ & Deletion & Prevention of neuron loss & 45 \\
\hline CX3CR1 & $A D$ & Deletion & Reduced plaque load & 47 \\
\hline CXCR2 & $A D$ & Deletion & Decreased $A \beta$ production & 105 \\
\hline $\mathrm{H} 2-\mathrm{BF} / \mathrm{C} 2$ & Prion disease & Deletion & Prevention of prion disease & 99 \\
\hline IFNGR1 & $A D$ & Deletion & Decreased plaque load and gliosis. & 106 \\
\hline $\mathrm{IL}-1 \beta$ & ALS & Deletion & Extended life span, decreased gliosis and neurodegeneration & 50 \\
\hline PTGER2 & $A D$ & Deletion & Decreased plaque load and oxidative damage & 107 \\
\hline RAG1 & PD & Deletion & Attenuation of neuronal cell death & 76 \\
\hline RAGE & $A D$ & Overexpression in neurons & Accelerated abnormalities in learning and memory & 29 \\
\hline RAGE & $A D$ & $\begin{array}{l}\text { Overexpression of dominant- } \\
\text { negative form in neurons }\end{array}$ & $\begin{array}{l}\text { Preservation of learning and memory, } \\
\text { decreased neurodegeneration }\end{array}$ & 29 \\
\hline S100B & $A D$ & $\begin{array}{l}\text { Overexpression under human } \\
\text { S100B promotor }\end{array}$ & Increased plaque load and gliosis & 108 \\
\hline TCRB & PD & Deletion & Attenuation of neuronal cell death & 76 \\
\hline TGF- $\beta 1$ & $A D$ & Overexpression in astrocytes & Increased amyloidosis in the cerebral vasculature & 109 \\
\hline TGFBR2 & $A D$ & $\begin{array}{l}\text { Dverexpression of dominant-negative } \\
\text { form in cells of the myeloid lineage }\end{array}$ & Decreased plaque load and vascular $A \beta$ deposition & 110 \\
\hline TNFR1 & $A D$ & Deletion & Decreased $A \beta$ generation and plaque load & 36 \\
\hline TNFR1/2 & PD & Deletion & Protection against dopaminergic cell death & 35 \\
\hline
\end{tabular}

AGenetic modification is present in all cells. C3, complement component 3; Crry, complement-receptor related protein; H2-BF, complement factor B; IFNGR1, IFN- $\gamma$ receptor 1; PTGER2, prostaglandin E2 receptor; RAG1, recombination activating gene 1; S100B, S100 calcium binding protein B.

recognition of abnormal molecular patterns, initiation of inflammatory pathways, and activation of autophagy. This mechanism may well be evolutionarily conserved and could allow cells to purge themselves of abnormal protein aggregates, aged mitochondria, or other cellular junk apart from intracellular pathogens. That such a scenario may, at least in part, take place in neurons in a cellautonomous way is supported by elegant studies demonstrating recognition of Sindbis virus capsid protein by the adaptor protein p62, leading to activation of autophagy and protection against virus-induced cell death (22). Additionally, studies in medicinal leech, which is able to regenerate the structure and function of its CNS after mechanical lesions (23), show that both intracellular leech NLR and TLR1 are temporally and spatially associated with regeneration of neurons (24). It will therefore be most interesting to test whether intracellular innate immune sensors are capable of recognizing abnormal patterns or assemblies of the disease-related proteins $\beta$-amyloid (A $\beta), \alpha$-synuclein, huntingtin, or TAR DNAbinding protein 43 (TDP43). It will also be important to determine in which cellular compartment such protein aggregates may be accessible to TLRs, NLRs, and related receptors.

Alerting the neighbors. Once neurons have detected cell intrinsic abnormalities, they will alert their neighbors, which include microglia, astrocytes, and possibly other, less abundant cells in the
CNS. Injured neurons can release ATP, ions, neurotransmitters, growth factors, cytokines, and other injury response factors, or they can retract inhibitory molecules that keep microglia in a quiet, surveillant state (25). Neurons may release nucleic acids or hsp, which are ligands for TLRs and other receptors, into the extracellular space. For example, hsp60 released from injured neurons can activate microglia via TLR4, causing enhanced nitric oxide production and in turn, neuronal cell death (26). An important mediator alerting other cells to neuronal injury is the DNA-binding protein high mobility group box 1 (HMGB1), which can be released actively from injured cells or passively from dying cells. HMGB1 promoted neurodegeneration in a mouse model of ischemic stroke by activating microglia through receptor for advanced glycation end products (RAGE) (27). Likewise, in a cellular model of Parkinson disease (PD) using the neurotoxin 1-methyl-4-phenyl-1,2,3,6-tetrahydropyridine (MPTP), HMGB1 binds to $\mathrm{CD} 11 \mathrm{~b} / \mathrm{Mac} 1$ on microglia to induce a neurotoxic response (28).

Neuronal sensing of tissue injury through immune receptors. Neurons are remarkably well equipped with immune receptors and sensor molecules to detect injury in their local environment. In addition to TLRs, they express cytokine and growth factor receptors, major histocompatibility class I, and complement receptors. While dozens of studies have manipulated immune pathways in mouse models of neurodegeneration (Tables 1 and 2), most used global or 


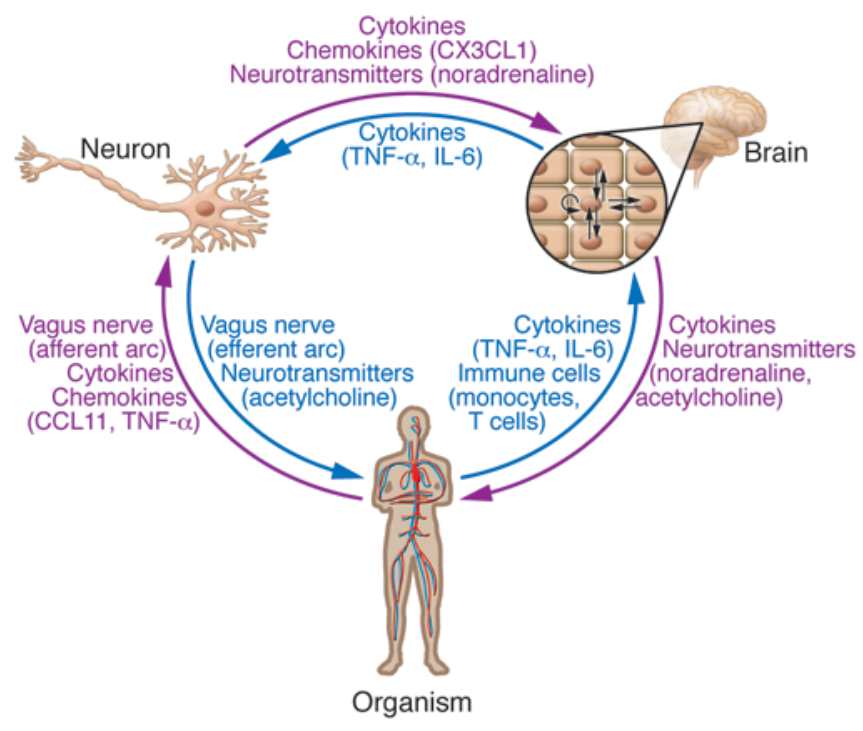

Figure 1

Immune-mediated interactions in neurodegeneration at the cellular, tissue, and systemic level. Immune interactions in neurodegeneration can occur within neurons, in the brain tissue, or in the systemic environment through cytokines, neurotransmitters, cell-cell interactions, and peripheral nerves. Abnormalities at any of these levels of organization may modulate neurodegenerative processes in the CNS and may also serve as targets for therapeutic interventions. Some of the factors discussed in more detail in the text are listed in the figure.

CNS-wide genetic manipulations, and it is unclear to what extent the effects are mediated through neurons, glial cells, or both. A notable exception was the directed expression of RAGE, one of several known receptors for $A \beta$, in neurons. These studies found that RAGE activates NF-KB and MAPK signaling and results in increased synaptic transmission deficits and cognitive impairment (29). Also, expression of a dominant-negative TGF- $\beta$ type II receptor in neurons impaired signaling in these cells and resulted in a two-fold increase in amyloid accumulation and increased neurodegeneration in mutant APP transgenic mice, a mouse model of familial Alzheimer disease (AD) (30). Because brains from patients with $\mathrm{AD}$ have significantly reduced levels of this TGF- $\beta$ receptor compared with those without disease (30), it is possible that deficiency in neuronal TGF- $\beta$ signaling may contribute to AD.

Recently an exciting approach to studying the effect of prostaglandins in the brain was described in a stroke model (31). The COX-2 product prostaglandin E2 can bind to four different prostanoid receptors making it difficult to understand how COX-2 inhibitors, which seem to strongly reduce risk of AD (32) and PD (33), work in the brain. Liang and coworkers showed that genetic deletion of prostanoid receptor 4 in neurons worsened stroke injury and decreased cerebral perfusion, pointing to a beneficial effect of this receptor in neurons (31). Clearly, this is a direction in which the field of neurodegeneration has to move in order to gain a more complete understanding of the complex action of immune factors in neuronal distress and degeneration.

\section{Local immune responses to distressed neurons}

When neurons send out distress signals, there is a strong response from CNS-resident immune cells such as microglia. What is most puzzling about this response is that rather than helping the injured neurons, more often than not microglia seem to harm or kill neurons. The logic of this action seems counterintuitive, but it may be that it is better for the brain as a whole to get rid of damaged neurons than to have them disrupt otherwise well-functioning circuits. Additionally, there may be more subtle differences in neuronal alarm signals, such that the typical immune response is actually beneficial, but the signal we have been able to study in cell culture systems or through the use of rather crude experimental tools in vivo is lethal. Future studies aiming at the earliest immune responses to neuronal injury using more sophisticated genetic tools and injury models may bring clarity to this conundrum.

Activated microglia can produce a large array of immune mediators including cytokines, chemokines, complement proteins, and nitric oxide, many of which have neurotoxic effects (25). For example, blocking TNF- $\alpha$ attenuates loss of dopaminergic neurons in mouse models of $\mathrm{PD}(34,35)$ and reduces pre-plaque pathology and learning and memory deficits in mouse models of $\mathrm{AD}(36,37)$. Attempts to divide microglia into functional subsets have been hampered by the lack of reliable cellular markers, which may be due in part to the plasticity of these cells and the possibility that they can assume a continuum of different activation states (38). In a surveillant state (previously erroneously referred to as "resting"), microglia sample their environment for danger signals (39) and they seem to maintain this state through a number of close interactions with neurons. If the neuronal ties are severed, microglia become activated and, depending on the context, may support nearby neurons or kill them. Neuronal-microglial ties include CD200 and CD200R or CD47 and CD172a, (each expressed on neurons and microglia, respectively) $(40,41)$. The best-studied of these cellular interactions is between neuronal fractalkine (CX3CL1) and the microglia-restricted fractalkine receptor (CX3CR1) (42). Mice that are genetically deficient in CX3CR1 display increased neurotoxicity in response to MPTP, overexpressed mutant SOD, and systemic LPS injections (43). Importantly, LPS toxicity was transferred by transplantation of CX3CR1-deficient microglia from LPS-treated mice into brains of wild-type mice, indicating that microglial toxicity is cell autonomous (43). In contrast, lack of CX3CR1 in a model of stroke reduced neuronal cell loss (44) and produced distinct effects in four independent mouse models for $\mathrm{AD}$ pathology (Tables 1 and 2). While CX3CR1 deficiency also reduced neuronal loss in mice that express a combination of familial AD mutations in APP, presenilin 1, and $\tau(45)$, it promoted neuronal $\tau$ pathology and behavioral deficits in mice that express only mutant $\tau$ (46). Furthermore, CX3CR1 deficiency reduced amyloid deposition, without reported effects on neurons, in mice expressing human mutant amyloid precursor protein (APP) alone or in combination with presenilin 1 (47).

How the same genetic defect can be both good and bad for neurons is still unclear, but it is likely that microglial function in vivo is shaped by signals from a multitude of receptor pathways. For example, the presence of other triggers of innate inflammatory pathways (e.g., TLR ligands) can induce caspase signaling in microglia, turning them into neurotoxic cells in vivo (48). Interestingly, SOD1 is required for activation of caspase-1, and thus production of mature IL-1, in response to LPS, suggesting a link between innate immune sensors and neurodegeneration. (49). Moreover, expression of an intracellular mutant SOD1 that is linked to genetic forms of amyotrophic lateral sclerosis (ALS) triggered an inflammasome response in microglia, and genetic deletion of caspase- 1 and IL-1 $1 \beta$ extended life span and reduced pathology in mutant SOD1 transgenic mice (Tables 1 and 2; ref. 50). 


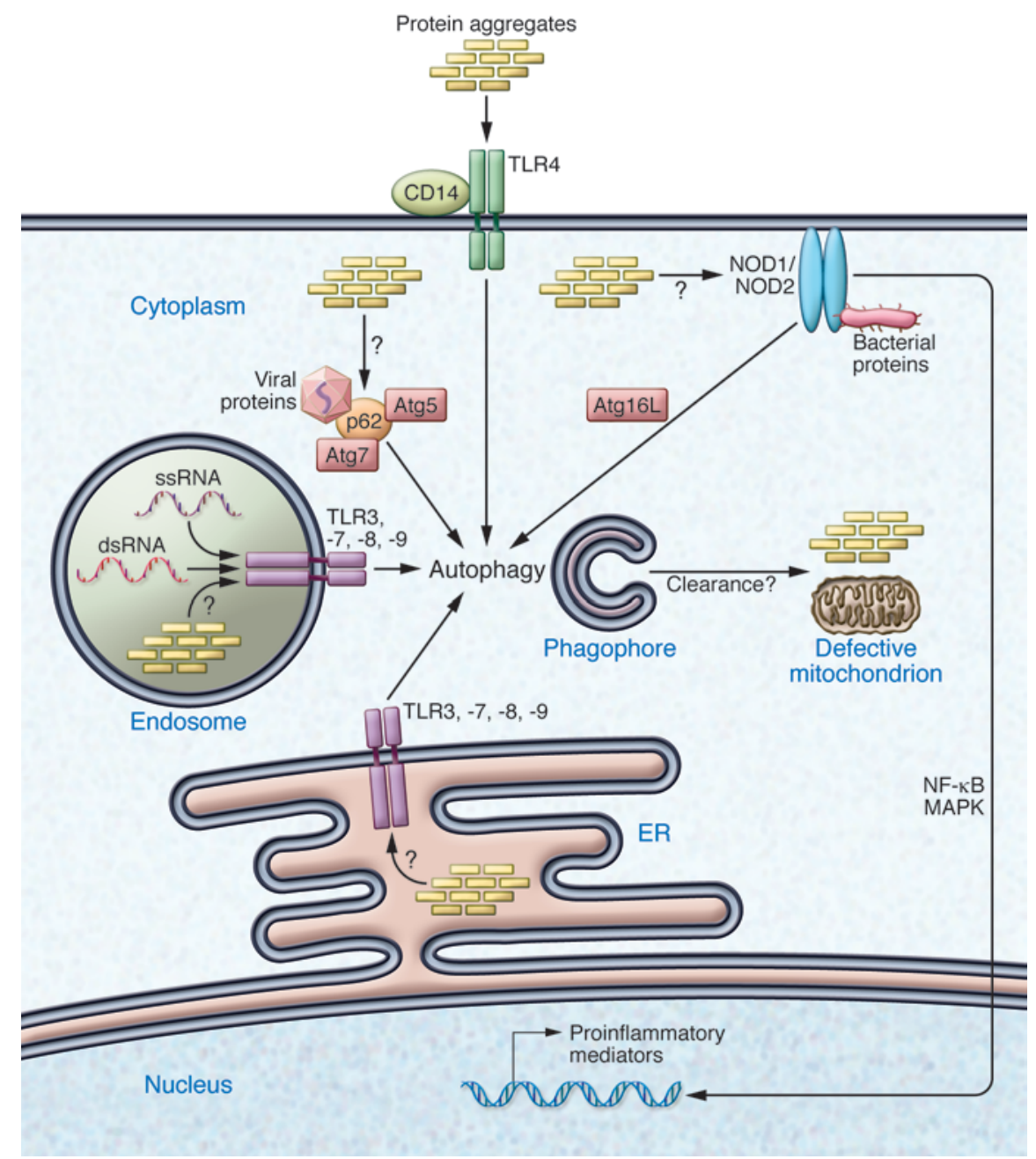

\section{Figure 2}

Innate immune receptors as sensors of intraneuronal distress. Neurons express innate immune receptors that serve as sensors of danger signals. TLRs may recognize endogenous molecules and protein aggregates such as $A \beta$ assemblies, ssRNA, or dsRNA aside from molecules associated with pathogens. While TLR4 and its co-receptor CD14 are present at the cell surface, TLR3, -7, -8, and -9 are located in the ER and endosomal compartments. Activation of TLRs can lead to initiation of autophagy via TRIF/RIP1 and possibly induce the clearance of defective organelles or protein aggregates. Activation of NOD1 or NOD2 may result in NF-KB-mediated transcription of pro-inflammatory genes or initiation of autophagy via Atg16L. The adaptor protein $\mathrm{p} 62$ can detect viral proteins in neurons and initiate clearance of viral particles via autophagy involving Atg5 and Atg7. It may also assist in the clearance of abnormal protein aggregates. Atg, autophagy-related protein; NOD, nucleotide binding oligomerization domain-like; p62, nucleoporin 62; TRIF, TIR domain-containing adapter-inducing IFN- $\beta$; RIP1, receptor interacting protein-1.
A key functional state that microglia can assume and that has received much attention recently is the phagocytic state. The clearance of cellular debris or protein aggregates is evidently a positive function of microglia, but phagocytosis of synapses - so-called synaptic pruning - or removal of entire neurites could be a doubleedged sword. For example, CX3CR1 deficiency results in increased numbers of dendritic spines and more immature synapses during postnatal brain development, suggesting a role for microglia in the removal of synapses and the maintenance of neuronal plasticity (51). After entorhinal cortex lesion, microglia are involved in the removal of denervated neural processes and reorganization of the brain, and again, CX3CR1 deficiency impairs this process (52). Although these studies suggest that CX3CR1 activation promotes phagocytosis, an independent study found that treatment with CX3CL1 reduces phagocytic engulfment of latex beads in cultured microglia and that mice lacking CX3CR1 show increased uptake of stereotaxically injected $A \beta$ fibrils into microglia (47). Clearly, more work is necessary to sort out these differences.

Microglial phagocytosis is also regulated by the purinergic receptor $\mathrm{P}_{2} \mathrm{Y}_{6}$, possibly upon binding of UDP released from injured neurons (53) or by complement proteins $\mathrm{C} 1 \mathrm{q}$ and $\mathrm{C} 3$, which have been linked to synaptic pruning during development (54). However, the role of microglia in (abnormal) synaptic pruning and removal of other neuronal structures in neurodegeneration is still unclear. Likewise, it is debated how much microglia contribute to the clearance of protein aggregates such as those that are characteristic of $\mathrm{AD}$. While several studies show that activation of microglia can lead to reduced $A \beta$ accumulation and plaque formation in APP transgenic mice (55-58), surprisingly, conditional deletion of microglia in two transgenic mouse models did not change $A \beta$ load or development of neuritic dystrophy (58). Since microglia are clearly capable of phagocytosing $\mathrm{A} \beta$ assemblies in vitro or on brain slices ex vivo $(59,60)$, it is possible that the engulfed peptide impairs intracellular degradation $(61,62)$ or that $A \beta$ or other age-related factors render microglia ineffective.

In addition to microglia, astrocytes become activated in response to neuronal injury, and they too can produce many classical immune factors with important functions in neuronal survival and death (4). Examples include the chemokine CCL2, TGF- $\beta 1$, IL-1, and IL-6, and some of their effects on amyloid deposition and neurodegeneration are listed in Tables 1 and 2 .

\section{Immune responses in the systemic environment}

Immune activation in neurons or the CNS can propagate to the organism as a whole and induce alterations in immune status. In turn, immune activation in the periphery can affect CNS cells and neurons (Figure 1). The blood-brain barrier (BBB), which is formed by endothelial cells, astrocytic end feet, and basement membrane, restricts access of larger molecules and cells from the 
Table 2

Genetic modifications in mouse models of neurodegenerative diseases: molecules with beneficial effects

\begin{tabular}{|c|c|c|c|c|}
\hline Molecule & Disease model for: & Genetic manipulation ${ }^{A}$ & Outcome & Reference \\
\hline Beclin 1 & $A D$ & Deletion (haplo-insufficiency) & Increased plaque load and neurodegeneration & 16 \\
\hline C3 & $A D$ & Deletion & Increased plaque load and neurodegeneration & 111 \\
\hline CCR1 & Prion disease & Deletion & More rapid disease progression & 112 \\
\hline CCR2 & $A D$ & Deletion & Increased $A \beta$ levels, decreased survival & 71 \\
\hline CCR2 & $A D$ & Deletion & Increased plaque load and memory impairment & 113 \\
\hline CCR2/CCL2 & PD & Deletion & No effect & 114 \\
\hline CCR5 & $A D$ & Deletion & Increased levels of endogenous mouse $A \beta 42$ & 115 \\
\hline CD45 & $A D$ & Deletion & Increased plaque load & 116 \\
\hline CX3CR1 & ALS & Deletion & $\begin{array}{l}\text { Increased neuron loss and microglial } \\
\text { activation, decreased survival }\end{array}$ & 43 \\
\hline CX3CR1 & PD & Deletion & Increased neuron loss and microglial activation & 43 \\
\hline IFN- $\gamma$ & $A D$ & $\begin{array}{l}\text { AAV-mediated overexpression } \\
\text { in brain }\end{array}$ & $\begin{array}{c}\text { Decreased plaque load, increased } \\
\text { microglial activation }\end{array}$ & 117 \\
\hline IL-1R1 & $A D$ & Deletion & No changes in plaque load & 118 \\
\hline IL-18 & ALS & Deletion & No changes in life span & 50 \\
\hline IL-1 $\beta$ & ALS & Deletion & No effect on life span or motor axon degeneration & 119 \\
\hline IL-1 $\beta$ & $A D$ & $\begin{array}{l}\text { Overexpression of active } \\
\quad \text { form in astrocytes }\end{array}$ & Decreased plaque load, increased gliosis & 120 \\
\hline IL-6 & $A D$ & $\begin{array}{l}\text { AAV-mediated overexpression } \\
\text { in the brain }\end{array}$ & Decreased plaque load, increased gliosis & 121 \\
\hline MyD88 & Prion disease & Deletion & No changes in infection or histopathology & 122 \\
\hline TGF- $\beta 1$ & $\mathrm{AD}$ & Overexpression in astrocytes & Decreased plaque load and neurodegeneration & 123 \\
\hline TGFBR2 & $A D$ & Deletion in neurons & Increased plaque load and dendritic loss & 30 \\
\hline TLR2 & $A D$ & Deletion & $\begin{array}{l}\text { Increased } A \beta \text { levels and accelerated } \\
\text { memory impairments }\end{array}$ & 124 \\
\hline TLR4 & $A D$ & Deletion & Increased plaque load & 125 \\
\hline
\end{tabular}

AGenetic modification is present in all cells. C3, complement component 3; IL-1R1, IL-1 receptor 1; MyD88, myeloid differentiation primary response gene 88; TGFBR2, TGF- $\beta$ receptor 2 .

blood to the CNS (63). In general, systemic immune molecules present in blood or tissues may signal to the brain through at least four different routes: active transport across the $\mathrm{BBB}$, signaling at the luminal side of the $\mathrm{BBB}$ and propagation of secondary factors into the CNS, diffusion via circumventricular organs, and signaling via peripheral nerves such as the vagus (64-66). Blood-based immune cells may gain access to the brain through transendothelial migration across the BBB into the perivascular space, via the choroid plexus and the cerebrospinal fluid, or through post-capillary venules at the pial surface (reviewed by ref. 67).

Immune cells infiltrating the brain. While infiltrating immune cells are critical in CNS diseases such as multiple sclerosis, the extent to which blood-borne cells have a role in classical neurodegeneration is less well understood. In the APP transgenic mouse model, recruitment of peripheral macrophages to plaques or perivascular spaces appears to have beneficial effects, and several reviews have discussed the clinical relevance and mechanistic underpinnings of these findings $(68,69)$. The chemokine CCL2 and its receptor CCR2 are strong candidates as mediators of macrophage infiltration into the CNS and have captured the attention of researchers (refs. 70, 71; Tables 1 and 2); a recently described model expressing red fluorescent protein from the CCR2 locus and GFP from the CX3CR1 locus may provide new opportunities to study migration of these cells (72).

Besides myeloid cells, $T$ lymphocytes have been detected in postmortem tissue of $\mathrm{AD}, \mathrm{PD}$, and ALS patients (73-75), and at least in corresponding mouse models, $\mathrm{T}$ cells may indeed have a functional role in the pathogenesis of these diseases. Accordingly, the MPTP mouse model of $\mathrm{PD}$ recapitulates the infiltration of $\mathrm{T}$ cells into the substantia nigra (76), and lack of $\mathrm{CD}^{+} \mathrm{T}$ cells attenuates dopaminergic cell death in a Fas ligand-dependent manner (76), suggesting a detrimental function of T cells in PD. In contrast, mutant SOD transgenic mouse models for ALS that are deficient in functional T cells display accelerated disease progression (77). It has been suggested that $\mathrm{T}$ cells exert a neuroprotective effect in this model by steering glial cells toward a neuroprotective phenotype (78).

Whether lymphocyte subset distribution in blood may be altered in humans with neurodegeneration remains to be shown. Though intriguing, most studies so far analyzed small numbers of patient samples and have not yet been replicated (reviewed in ref. 2). In order to determine whether immune cell abnormalities could provide information about disease state or severity, large, independent studies need to be conducted.

Systemic immune mediators associated with neurodegeneration. Systemic inflammation after major surgery or infection often causes delirium in people, and the probability of this complication increases with age (79) and may result in increased risk of dementia or mortality $(80,81)$. For example, a study in patients with moderate to severe AD showed that acute systemic inflammation leads to a more rapid decline in cognitive function, possibly due to increased levels of circulating TNF- $\alpha$ (82). In APP transgenic animal models, systemic challenge with LPS - to mimic peripheral inflammation - can result in enhanced amyloid deposition and more severe memory impairment (83). Similar results, with exacerbated disease progression and pathology following systemic LPS administration, have been observed in animal models of ALS and Prion disease (84-86). 
A growing number of studies recognize TNF- $\alpha$ as a main perpetrator in cognitive dysfunction associated with systemic inflammation or injury. Thus, peripheral injection of LPS into wild-type mice can lead to prolonged increases in cerebral TNF- $\alpha$ levels and loss of dopaminergic neurons in the substantia nigra, effects which are ameliorated in mice lacking both TNF- $\alpha$ receptors (87). TNF- $\alpha$ was also shown to be a main mediator of post-operative cognitive dysfunction following orthopedic surgery in mice (88). Interestingly, TNF- $\alpha$ may also have a role in familial forms of frontotemporal dementia (FTD) with loss-of-function mutations in progranulin. This anti-inflammatory protein was shown recently to bind to TNF- $\alpha$ receptors and inhibit TNF- $\alpha$-mediated inflammation in a mouse model of arthritis (89), and it is conceivable that it has similar functions in FTD.

Systemic immunity can be coordinated by neural circuits that operate reflexively. The central components of this immunological reflex are the afferent and the efferent arc of the vagus nerve, which sense and inhibit the production of pro-inflammatory cytokines, respectively. Vagus nerve stimulation leads to release of noradrenaline and subsequently acetylcholine in the spleen, which suppresses the generation of pro-inflammatory cytokines such as TNF- $\alpha$ (65). Not much work has been done on the effects of the vagus nerve in neurodegenerative diseases, but clearly this exciting field warrants a close look. Interestingly, vagus nerve stimulation seems to reduce or slow cognitive decline in some patients with $\mathrm{AD}(90)$.

Additional evidence linking systemic inflammation with neurodegeneration comes from epidemiological studies, which show that prolonged use of nonsteroidal anti-inflammatory drugs (NSAIDs) reduces the risk of developing AD (32) or PD (33) by as much as $50 \%$. These beneficial effects do not extend into the clinical phase of disease, and clinical trials using several different NSAIDs have not resulted in cognitive improvement (91). While it may simply be too late to target inflammation with these drugs once clinical symptoms are apparent, it is equally possible that more specific modulators of inflammatory processes targeting, for instance, prostanoid receptors, would show benefits.

Additional evidence that neurodegeneration is associated with systemic changes in the immune response comes also from screens of peripheral blood cell transcriptomes (92) and of cellular signaling proteins (93) in blood from patients with $\mathrm{AD}$ and controls. While such studies are still underpowered and proteomic studies suffer from technical challenges, our group was recently successful in identifying several overlapping proteins in two studies, which used different detection methods and samples (94). Among these proteins, G-CSF and macrophage-CSF were reduced in the plasma of $\mathrm{AD}$ patients in studies conducted by our group and led to reduced amyloidosis and neuroinflammation in APP transgenic mice following systemic administration by two independent groups $(95,96)$. These results suggest that changes in peripheral immune factors can influence neurodegenerative processes. Interestingly, cognitive decline with aging may be linked, in part, to increased levels of inflammatory protein in the systemic environment. These factors in the blood of old mice were capable of inhibiting hippocampus-dependent spatial learning and memory, long-term potentiation, and adult hippocampal neurogenesis in young mice, and systemic injection of one of these factors, CCL11/eotaxin, was sufficient to elicit some of these effects (97). Together, these observations provide the intriguing possibility that the peripheral immune environment in neurodegenerative diseases could be targeted toward the development of novel therapies that regulate CNS function to slow cognitive decline and neurodegeneration.

\section{Conclusion}

While it took 36 years to generate the first 1,200 publications containing the key words "immunology" and "neurodegeneration," it took only 9 more years to double that number. The small fraction of these studies discussed here make it clear that immune responses are integral to neurodegeneration and that we are just at the beginning of understanding this complex relationship. Exciting new studies linking innate immune receptors to cellular protein homeostasis through phagocytosis and autophagy may provide new insight into immune dysfunction and neurodegeneration. Rapid progress is also being made in our understanding of microglia, both as protectors of neurons and as their possibly worst enemy. Fortunately, we can make active progress toward the development of useful therapies even as research into the basic mechanisms continues.

\section{Acknowledgments}

The authors thank Kira Mosher and Kurt Lucin for insightful comments on the review. Additionally, the authors thank Gregor Bieri for drawing Figure 1. This work was supported by funds from the Department of Veterans Affairs (to T. Wyss-Coray), the NIH Institute on Aging (grant R01 AG030144, to T. WyssCoray), a California Institute for Regenerative Medicine Award (to T. Wyss-Coray), and funds from the Alexander von Humboldt Foundation (to E. Czirr).

Address correspondence to: Tony Wyss-Coray, Stanford University School of Medicine, 1201 Welch Road, Rm. P208, MSLS Bldg., Stanford, California 94305-5489, USA. Phone: 650.852.3220; Fax: 650.849.1983; E-mail: twc@stanford.edu.
1. Matzinger P. The danger model: a renewed sense of self. Science. 2002;296(5566):301-305.

2. Britschgi M, Wyss-Coray T. Systemic and acquired immune responses in Alzheimer's disease. Int Rev Neurobiol. 2007;82:205-233.

3. Wyss-Coray T, Mucke L. Inflammation in neurodegenerative disease: A double-edged sword. Neuron. 2002;35(3):419-432.

4. Akiyama H, Arai T, Kondo H, Tanno E, Haga C, Ikeda K. Cell mediators of inflammation in the Alzheimer disease brain. Alzheimer Dis Assoc Disord. 2000;14 suppl 1:S47-S53.

5. Iwasaki A, Medzhitov R. Toll-like receptor control of the adaptive immune responses. Nat Immunol. 2004;5(10):987-995.

6. Okun E, Griffioen KJ, Mattson MP. Toll-like recep- tor signaling in neural plasticity and disease. Trends Neurosci. 2011;34(5):269-281.

7. Matsumoto $M$, et al. Subcellular localization of Toll-like receptor 3 in human dendritic cells. J Immunol. 2003;171(6):3154-3162.

8. Leifer CA, Kennedy MN, Mazzoni A, Lee C, Kruhlak MJ, Segal DM. TLR9 is localized in the endoplasmic reticulum prior to stimulation. J Immunol. 2004; 173(2):1179-1183.

9. Zhang Q, et al. Circulating mitochondrial DAMPs cause inflammatory responses to injury. Nature. 2010; 464(7285):104-107.

10. Delgado MA, Elmaoued RA, Davis AS, Kyei G, Deretic V. Toll-like receptors control autophagy. EMBO J. 2008;27(7):1110-1121.

11. Xu Y, Jagannath C, Liu XD, Sharafkhaneh A,
Kolodziejska KE, Eissa NT. Toll-like receptor 4 is a sensor for autophagy associated with innate immunity. Immunity. 2007;27(1):135-144.

12. Jaeger PA, Wyss-Coray T. All-you-can-eat: autophagy in neurodegeneration and neuroprotection. $\mathrm{Mol}$ Neurodegener. 2009;4:16.

13. Webb JL, Ravikumar B, Atkins J, Skepper JN, Rubinsztein DC. Alpha-Synuclein is degraded by both autophagy and the proteasome. J Biol Chem. 2003; 278(27):25009-25013.

14. Ravikumar B, Rubinsztein DC. Can autophagy protect against neurodegeneration caused by aggregate-prone proteins? Neuroreport. 2004; 15(16):2443-2445.

15. Yu WH, et al. Macroautophagy--a novel \{beta\}amyloid peptide-generating pathway activated in 
Alzheimer's disease. J Cell Biol. 2005;171(1):87-98.

16. Pickford F, et al. The autophagy-related protein beclin 1 shows reduced expression in early Alzheimer disease and regulates amyloid beta accumulation in mice. J Clin Invest. 2008;118(6):2190-2199.

17. Philpott DJ, Yamaoka S, Israel A, Sansonetti PJ. Invasive Shigella flexneri activates NF-kappa B through a lipopolysaccharide-dependent innate intracellular response and leads to IL-8 expression in epithelial cells. J Immunol. 2000;165(2):903-914.

18. Girardin SE, et al. CARD4/Nod1 mediates NFkappaB and JNK activation by invasive Shigella flexneri. EMBO Rep. 2001;2(8):736-742.

19. Travassos LH, et al. Nod1 and Nod2 direct autophagy by recruiting ATG16L 1 to the plasma membrane at the site of bacterial entry. Nat Immunol. 2010; 11(1):55-62.

20. Homer CR, Richmond AL, Rebert NA, Achkar JP, McDonald C. ATG16L1 and NOD2 interact in an autophagy-dependent antibacterial pathway implicated in Crohn's disease pathogenesis. Gas troenterology. 2010;139(5):1630-1641.

21. Yano T, et al. Autophagic control of listeria through intracellular innate immune recognition in drosophila. Nat Immunol. 2008;9(8):908-916.

22. Orvedahl A, MacPherson S, Sumpter R Jr, Talloczy Z, Zou Z, Levine B. Autophagy protects against Sindbis virus infection of the central nervous system. Cell Host Microbe. 2010;7(2):115-127.

23. Meriaux C, et al. Multiple changes in peptide and lipid expression associated with regeneration in the nervous system of the medicinal leech. PLoS One. 2011;6(4):e18359.

24. Cuvillier-Hot V, Boidin-Wichlacz C, Slomianny C, Salzet M, Tasiemski A. Characterization and immune function of two intracellular sensors, HmTLR1 and HmNLR, in the injured CNS of an invertebrate. Dev Comp Immunol. 2011;35(2):214-226.

25. Hanisch UK, Kettenmann H. Microglia: active sensor and versatile effector cells in the normal and pathologic brain. Nat Neurosci. 2007;10(11):1387-1394.

26. Lehnardt $\mathrm{S}$, et al. A vicious cycle involving release of heat shock protein 60 from injured cells and activation of toll-like receptor 4 mediates neurodegeneration in the CNS. J Neurosci. 2008;28(10):2320-2331.

27. Muhammad S, et al. The HMGB1 receptor RAGE mediates ischemic brain damage. J Neurosci. 2008 28(46):12023-12031.

28. Gao HM, Zhou H, Zhang F, Wilson BC, Kam W, Hong JS. HMGB1 acts on microglia Mac1 to mediate chronic neuroinflammation that drives progressive neurodegeneration. J Neurosci. 2011; 31(3):1081-1092

29. Arancio O, et al. RAGE potentiates Abeta-induced perturbation of neuronal function in transgenic mice. EMBOJ. 2004;23(20):4096-4105

30. Tesseur I, et al. Deficiency in neuronal TGF-beta signaling promotes neurodegeneration and Alzheimer's pathology. JClin Invest. 2006;116(11):3060-3069.

31. Liang X, et al. Signaling via the prostaglandin E2 receptor EP4 exerts neuronal and vascular protection in a mouse model of cerebral ischemia. J Clin Invest. 2011;121(11):4362-4371.

32. in ' $t$ Veld BA, et al. NSAIDs and incident Alzheimer's disease. The Rotterdam Study. Neurobiol Aging. 1998;19(6):607-611.

33. Gao X, Chen H, Schwarzschild MA, Ascherio A. Use of ibuprofen and risk of Parkinson disease. Neurology. 2011;76(10):863-869.

34. McCoy MK, et al. Blocking soluble tumor necrosis factor signaling with dominant-negative tumor necrosis factor inhibitor attenuates loss of dopaminergic neurons in models of Parkinson's disease. J Neurosci. 2006;26(37):9365-9375.

35. Sriram K, Matheson JM, Benkovic SA, Miller DB, Luster MI, O'Callaghan JP. Mice deficient in TNF receptors are protected against dopaminergic neurotoxicity: implications for Parkinson's disease.
FASEB J. 2002;16(11):1474-1476.

36. He P, et al. Deletion of tumor necrosis factor death receptor inhibits amyloid beta generation and prevents learning and memory deficits in Alzheimer's mice. J Cell Biol. 2007;178(5):829-841.

37. McAlpine FE, et al. Inhibition of soluble TNF signaling in a mouse model of Alzheimer's disease prevents pre-plaque amyloid-associated neuropathology. Neurobiol Dis. 2009;34(1):163-177.

38. Mosser DM, Edwards JP. Exploring the full spectrum of macrophage activation. Nat Rev Immunol. 2008; 8(12):958-969.

39. Nimmerjahn A, Kirchhoff F, Helmchen F. Resting microglial cells are highly dynamic surveillants of brain parenchyma in vivo. Science. 2005 ; 308(5726):1314-1318.

40. Hoek RM, et al. Down-regulation of the macrophage lineage through interaction with OX2 (CD200). Science. 2000;290(5497):1768-1771.

41. Oldenborg PA, Gresham HD, Lindberg FP. CD47signal regulatory protein alpha (SIRPalpha) regulates Fcgamma and complement receptor-mediated phagocytosis. J Exp Med. 2001;193(7):855-862.

42. Hatori K, Nagai A, Heisel R, Ryu JK, Kim SU. Fractalkine and fractalkine receptors in human neurons and glial cells. J Neurosci Res. 2002;69(3):418-426.

43. Cardona AE, et al. Control of microglial neurotoxicity by the fractalkine receptor. Nat Neurosci. 2006; 9(7):917-924

44. Denes A, Ferenczi S, Halasz J, Kornyei Z, Kovacs $\mathrm{KJ}$. Role of CX3CR1 (fractalkine receptor) in brain damage and inflammation induced by focal cerebral ischemia in mouse. J Cereb Blood Flow Metab. 2008; 28(10):1707-1721.

45. Fuhrmann M, et al. Microglial Cx3cr1 knockout prevents neuron loss in a mouse model of Alzheimer's disease. Nat Neurosci. 2010;13(4):411-413.

46. Bhaskar K, Konerth M, Kokiko-Cochran ON, Cardona A, Ransohoff RM, Lamb BT. Regulation of tau pathology by the microglial fractalkine receptor. Neuron. 2010;68(1):19-31.

47. Lee $\mathrm{S}$, et al. CX3CR1 deficiency alters microglial activation and reduces beta-amyloid deposition in two Alzheimer's disease mouse models. Am J Pathol. 2010;177(5):2549-2562.

48. Burguillos MA, et al. Caspase signalling controls microglia activation and neurotoxicity. Nature. 2011; 472(7343):319-324

49. Meissner F, Molawi K, Zychlinsky A. Superoxide dismutase 1 regulates caspase- 1 and endotoxic shock. Nat Immunol. 2008;9(8):866-872.

50. Meissner F, Molawi K, Zychlinsky A. Mutant superoxide dismutase 1-induced IL-1beta accelerates ALS pathogenesis. Proc Natl Acad Sci U S A. 2010; 107(29):13046-13050.

51. Paolicelli RC, et al. Synaptic pruning by microglia is necessary for normal brain development. Science. 2011;333(6048):1456-1458

52. Rappert A, et al. CXCR3-dependent microglial recruitment is essential for dendrite loss after brain lesion. J Neurosci. 2004;24(39):8500-8509.

53. Koizumi S, et al. UDP acting at P2Y6 receptors is a mediator of microglial phagocytosis. Nature. 2007;446(7139):1091-1095

54. Stevens B, et al. The classical complement cascade mediates CNS synapse elimination. Cell. 2007; 131(6):1164-1178

55. Herber DL, et al. Time-dependent reduction in Abeta levels after intracranial LPS administration in APP transgenic mice. Exp Neurol. 2004;190(1):245-253.

56. Wilcock DM, Munireddy SK, Rosenthal A, Ugen $\mathrm{KE}$, Gordon MN, Morgan D. Microglial activation facilitates Abeta plaque removal following intracranial anti-Abeta antibody administration. Neurobiol Dis. 2004;15(1):11-20.

57. Wyss-Coray T, et al. TGF-beta1 promotes microglial amyloid-beta clearance and reduces plaque burden in transgenic mice. Nat Med. 2001;7(5):612-618.
58. Grathwohl SA, et al. Formation and maintenance of Alzheimer's disease beta-amyloid plaques in the absence of microglia. Nat Neurosci. 2009; 12(11):1361-1363.

59. Koenigsknecht J, Landreth G. Microglial phagocytosis of fibrillar beta-amyloid through a beta1 integrin-dependent mechanism. J Neurosci. 2004; 24(44):9838-9846.

60. Bard F, et al. Peripherally administered antibodies against amyloid $\beta$-peptide enter the central nervous system and reduce pathology in a mouse model of Alzheimer disease. Nat Med. 2000;6(8):916-919.

61. Paresce DM, Chung H, Maxfield FR. Slow degradation of aggregates of the Alzheimer's disease amyloid beta-protein by microglial cells. J Biol Chem. 1997; 272(46):29390-29397.

62. Frackowiak J, Wisniewski HM, Wegiel J, Merz GS, Iqbal K, Wang KC. Ultrastructure of the microglia that phagocytose amyloid and the microglia that produce beta-amyloid fibrils. Acta Neuropathol. 1992; 84(3):225-233

63. Abbott NJ, Ronnback L, Hansson E. Astrocyteendothelial interactions at the blood-brain barrier. Nat Rev Neurosci. 2006;7(1):41-53.

64. Rosas-Ballina M, Tracey KJ. The neurology of the immune system: neural reflexes regulate immunity. Neuron. 2009;64(1):28-32.

65. Rosas-Ballina M, Tracey KJ. Cholinergic control of inflammation. J Intern Med. 2009;265(6):663-679.

66. Tracey KJ. Reflex control of immunity. Nat Rev Immunol. 2009:9(6):418-428.

67. Ransohoff RM, Kivisakk P, Kidd G. Three or more routes for leukocyte migration into the central nervous system. Nat Rev Immunol. 2003;3(7):569-581.

68. Ransohoff RM, Cardona AE. The myeloid cells of the central nervous system parenchyma. Nature. 2010; 468(7321):253-262.

69. Prinz M, Priller J, Sisodia SS, Ransohoff RM. Heterogeneity of CNS myeloid cells and their roles in neurodegeneration. Nat Neurosci. 2011;14(10):1227-1235.

70. D'Mello C, Le T, Swain MG. Cerebral microglia recruit monocytes into the brain in response to tumor necrosis factoralpha signaling during peripheral organ inflammation. J Neurosci. 2009; 29(7):2089-2102.

71. El Khoury J, et al. Ccr2 deficiency impairs microglial accumulation and accelerates progression of Alzheimer-like disease. Nat Med. 2007;13(4):432-438.

72. Saederup N, et al. Selective chemokine receptor usage by central nervous system myeloid cells in CCR2-red fluorescent protein knock-in mice. PLoS One. 2010;5(10):e13693

73. Engelhardt JI, Tajti J, Appel SH. Lymphocytic infiltrates in the spinal cord in amyotrophic lateral sclerosis. Arch Neurol. 1993;50(1):30-36.

74. Rogers J, Luber-Narod J, Styren SD, Civin WH. Expression of immune system-associated antigens by cells of the human central nervous system: relationship to the pathology of Alzheimer's disease. Neurobiol Aging. 1988;9(4):339-349.

75. McGeer PL, Itagaki S, Akiyama H, McGeer EG. Rate of cell death in parkinsonism indicates active neuropathological process. Ann Neurol. 1988; 24(4):574-576

76. Brochard V, et al. Infiltration of CD4+ lymphocytes into the brain contributes to neurodegeneration in a mouse model of Parkinson disease. JClin Invest. 2009; 119(1):182-192.

77. Beers DR, Henkel JS, Zhao W, Wang J, Appel SH. CD4+ T cells support glial neuroprotection, slow disease progression, and modify glial morphology in an animal model of inherited ALS. Proc Natl Acad Sci US A. 2008;105(40):15558-15563

78. Chiu IM, et al. T lymphocytes potentiate endogenous neuroprotective inflammation in a mouse model of ALS. Proc Natl Acad Sci U S A. 2008; 105(46):17913-17918.

79. Ehlenbach WJ, et al. Association between acute care 
and critical illness hospitalization and cognitive function in older adults. JAMA. 2010;303(8):763-770.

80. Newman MF, et al. Longitudinal assessment of neurocognitive function after coronary-artery bypass surgery. N EnglJ Med. 2001;344(6):395-402.

81. Moller JT, et al. Long-term postoperative cognitive dysfunction in the elderly ISPOCD1 study. ISPOCD investigators. International Study of PostOperative Cognitive Dysfunction. Lancet. 1998; 351(9106):857-861.

82. Holmes C, et al. Systemic inflammation and disease progression in Alzheimer disease. Neurology. 2009; 73(10):768-774.

83. Lee JW, et al. Neuro-inflammation induced by lipopolysaccharide causes cognitive impairment through enhancement of beta-amyloid generation. J Neuroinflammation. 2008;5:37.

84. Nguyen MD, D’Aigle T, Gowing G, Julien JP, Rivest $\mathrm{S}$. Exacerbation of motor neuron disease by chronic stimulation of innate immunity in a mouse model of amyotrophic lateral sclerosis. J Neurosci. 2004; 24(6):1340-1349.

85. Murray CL, Skelly DT, Cunningham C. Exacerbation of CNS inflammation and neurodegeneration by systemic LPS treatment is independent of circulating IL-1beta and IL-6. J Neuroinflammation. 2011;8:50.

86. Cunningham C, Wilcockson DC, Campion S, Lunnon K, Perry VH. Central and systemic endotoxin challenges exacerbate the local inflammatory response and increase neuronal death during chronic neurodegeneration. J Neurosci. 2005; 25(40):9275-9284.

87. Qin L, et al. Systemic LPS causes chronic neuroinflammation and progressive neurodegeneration. Glia. 2007;55(5):453-462.

88. Terrando N, Monaco C, Ma D, Foxwell BM, Feldmann M, Maze M. Tumor necrosis factor-alpha triggers a cytokine cascade yielding postoperative cognitive decline. Proc Natl Acad Sci U S A. 2010; 107(47):20518-20522.

89. Tang W, et al. The growth factor progranulin binds to TNF receptors and is therapeutic against inflammatory arthritis in mice. Science. 2011; 332(6028):478-484.

90. Merrill CA, et al. Vagus nerve stimulation in patients with Alzheimer's disease: Additional follow-up results of a pilot study through 1 year. J Clin Psychiatry. 2006;67(8):1171-1178.

91. Imbimbo BP. An update on the efficacy of non-steroidal anti-inflammatory drugs in Alzheimer's disease. Expert Opin Investig Drugs. 2009;18(8):1147-1168.

92. Booij BB, et al. A gene expression pattern in blood for the early detection of Alzheimer's disease. J Alzheimers Dis. 2011;23(1):109-119.

93. Ray S, et al. Classification and prediction of clinical Alzheimer's diagnosis based on plasma signaling proteins. Nat Med. 2007;13(11):1359-1362.

94. Britschgi $\mathrm{M}$, et al. Modeling of pathological traits in Alzheimer's disease based on systemic extracellular signaling proteome. Mol Cell Proteomics. 2011;10(10):M111.008862
95. Boyd TD, et al. GM-CSF upregulated in rheumatoid arthritis reverses cognitive impairment and amyloidosis in Alzheimer mice. J Alzheimers Dis. 2010;21(2):507-518.

96. Sanchez-Ramos J, et al. Granulocyte colony stimulating factor decreases brain amyloid burden and reverses cognitive impairment in Alzheimer's mice. NeuroScience. 2009;163(1):55-72.

97 . Villeda SA, et al. The ageing systemic milieu negatively regulates neurogenesis and cognitive function. Nature. 2011;477(7362):90-94.

98. Fonseca MI, Zhou J, Botto M, Tenner AJ. Absence of $\mathrm{C} 1 \mathrm{q}$ leads to less neuropathology in transgenic mouse models of Alzheimer's disease. JNeurosci. 2004; 24(29):6457-6465.

99. Klein MA, et al. Complement facilitates early prion pathogenesis. Nat Med. 2001;7(4):488-492.

100.Yamamoto $M$, et al. Overexpression of monocyte chemotactic protein-1/CCL2 in beta-amyloid precursor protein transgenic mice show accelerated diffuse beta-amyloid deposition. Am J Pathol. 2005; 166(5):1475-1485.

101. Reed-Geaghan EG, Reed QW, Cramer PE, Landreth GE. Deletion of CD14 attenuates Alzheimer's disease pathology by influencing the brain's inflammatory milieu. J Neurosci. 2010;30(46):15369-15373.

102.Park L, et al. Scavenger receptor CD36 is essential for the cerebrovascular oxidative stress and neurovascular dysfunction induced by amyloid-beta. Proc Natl Acad Sci U S A. 2011;108(12):5063-5068

103. Tan J, et al. Role of CD40 ligand in amyloidosis in transgenic Alzheimer's mice. Nat Neurosci. 2002; 5(12):1288-1293.

104.Wyss-Coray T, et al. Prominent neurodegeneration and increased plaque formation in complementinhibited Alzheimer's mice. Proc Natl Acad Sci US A. 2002;99(16):10837-10842.

105.Bakshi P, Margenthaler E, Reed J, Crawford F, Mullan M. Depletion of CXCR2 inhibits gammasecretase activity and amyloid-beta production in a murine model of Alzheimer's disease. Cytokine. 2011; 53(2):163-169.

106. Yamamoto $M$, et al. Interferon-gamma and tumor necrosis factor-alpha regulate amyloid-beta plaque deposition and beta-secretase expression in Swedish mutant APP transgenic mice. Am J Pathol. 2007; 170(2):680-692.

107. Liang X, et al. Deletion of the prostaglandin E2 EP2 receptor reduces oxidative damage and amyloid burden in a model of Alzheimer's disease. J Neurosci. 2005;25(44):10180-10187.

108.Mori T, Koyama N, Arendash GW, HorikoshiSakuraba Y, Tan J, Town T. Overexpression of human S100B exacerbates cerebral amyloidosis and gliosis in the Tg2576 mouse model of Alzheimer's disease. Glia. 2010;58(3):300-314.

109. Wyss-Coray T, et al. Amyloidogenic role of cytokine TGF-beta 1 in transgenic mice and in Alzheimer's disease. Nature. 1997;389(6651):603-606

110. Town T, et al. Blocking TGF-beta-Smad $2 / 3$ innate immune signaling mitigates Alzheimer-like pathology. Nat Med. 2008;14(6):681-687.
111. Maier M, Peng Y, Jiang L, Seabrook TJ, Carroll MC, Lemere CA. Complement C3 deficiency leads to accelerated amyloid beta plaque deposition and neurodegeneration and modulation of the microglia/ macrophage phenotype in amyloid precursor protein transgenic mice. J Neurosci. 2008;28(25):6333-6341.

112. LaCasse RA, Striebel JF, Favara C, Kercher L, Chesebro B. Role of Erk1/2 activation in prion disease pathogenesis: absence of CCR1 leads to increased Erk1/2 activation and accelerated disease progression. J Neuroimmunol. 2008;196(1-2):16-26.

113. Naert G, Rivest S. CC chemokine receptor 2 deficiency aggravates cognitive impairments and amyloid pathology in a transgenic mouse model of Alzheimer's disease. J Neurosci. 2011;31(16):6208-6220.

114. Kalkonde YV, et al. Chemokines in the MPTP model of Parkinson's disease: absence of CCL2 and its receptor CCR2 does not protect against striatal neurodegeneration. Brain Res. 2007;1128(1):1-11.

115. Lee YK, et al. CCR5 deficiency induces astrocyte activation, Abeta deposit and impaired memory function. Neurobiol Learn Mem. 2009;92(3):356-363.

116.Zhu Y, et al. CD45 deficiency drives amyloid-beta peptide oligomers and neuronal loss in Alzheimer's disease mice. J Neurosci. 2011;31(4):1355-1365.

117. Chakrabarty P, et al. IFN-gamma promotes complement expression and attenuates amyloid plaque deposition in amyloid beta precursor protein transgenic mice. J Immunol. 2010;184(9):5333-5343.

118. Das P, et al. Interleukin-1 receptor 1 knockout has no effect on amyloid deposition in Tg2576 mice and does not alter efficacy following Abeta immunotherapy. J Neuroinflammation. 2006;3:17.

119.Nguyen MD, Julien JP, Rivest S. Induction of proinflammatory molecules in mice with amyotrophic lateral sclerosis: no requirement for proapoptotic interleukin-1beta in neurodegeneration. Ann Neurol. 2001;50(5):630-639.

120.Shaftel SS, Kyrkanides S, Olschowka JA, Miller JN, Johnson RE, O'Banion MK. Sustained hippocampal IL-1 beta overexpression mediates chronic neuroinflammation and ameliorates Alzheimer plaque pathology. J Clin Invest. 2007;117(6):1595-1604.

121. Chakrabarty $\mathrm{P}$, et al. Massive gliosis induced by interleukin-6 suppresses Abeta deposition in vivo: evidence against inflammation as a driving force for amyloid deposition. FASEB J. 2010;24(2):548-559.

122.Prinz M, Heikenwalder M, Schwarz P, Takeda $\mathrm{K}$, Akira S, Aguzzi A. Prion pathogenesis in the absence of Toll-like receptor signalling. EMBO Rep. 2003;4(2):195-199.

123 . Wyss-Coray T, et al. TGF- $\beta 1$ promotes microglial amyloid- $\beta$ clearance and reduces plaque burden in transgenic mice. Nat Med. 2001;7(5):612-618.

124. Richard KL, Filali M, Prefontaine P, Rivest S. Tolllike receptor 2 acts as a natural innate immune receptor to clear amyloid beta 1-42 and delay the cognitive decline in a mouse model of Alzheimer's disease. J Neurosci. 2008;28(22):5784-5793.

125. Tahara K, Kim HD, Jin JJ, Maxwell JA, Li L, Fukuchi $\mathrm{K}$. Role of toll-like receptor signalling in Abeta uptake and clearance. Brain. 2006;129(pt 11):3006-3019. 